\title{
THE EFFECT OF PSYCHOLOGICAL CAPITAL ON GROWTH AND ENTREPRENEURS' USE OF HUMAN AND SOCIAL CAPITAL
}

\author{
SUSAN SCHWARZ \\ Aston Business School \\ Aston Triangle, Birmingham B4 7ET, UK
}

INTRODUCTION

A primary question in entrepreneurship research is why some individuals are more successful than others in launching and growing businesses. To address this question, research focuses on entrepreneurs' individual characteristics and motivations (Baum \& Locke, 2004), including human capital (Estrin et al., 2016; Unger et al., 2011), while a separate stream of research addresses links between social capital and venture performance (Gedajlovic et al., 2013; Stam et al., 2014). Individuals interact with networks to gain access to resources (Batjargal, 2003; Lin, 2001) and to navigate the entrepreneurial process, including guanxi networks in China (Chen et al., 2013; Lin, 2017). The application of these 'capitals' is a key source of competitive advantage (Bourdieu, 1986; De Clercq et al., 2013), given challenging conditions facing businesses in emerging-economy environments (Tang, 2010; Du \& Mickiewicz, 2016).

Despite the value of human capital such as education and experience to entrepreneurs, inconsistent effects on growth are also seen (Cassar, 2014; Davidsson \& Honig, 2003). Similarly, entrepreneurs' social networks may generate both positive and negative returns (Florin et al., 2003; Guo \& Miller, 2010; Kreiser et al., 2013). These mixed findings suggest that additional elements are needed for entrepreneurs to deploy resources effectively, for instance, leveraging social networks (Batjargal, 2010; Fang et al., 2015). Thus, scholars have called for examination of moderators to the effects of human capital and social capital on venture outcomes (Baron, 2007; Marvel et al., 2016; Hoang \& Yi, 2015).

A growing body of literature has introduced psychological capital as an individual's "positive psychological state of development" (Luthans et al., 2007a, 2007b: 2). Comprising four sub-dimensions - self-efficacy, optimism, hope, and resilience - psychological capital has positive effects on work outcomes in many organizational settings (Luthans \& Youssef, 2004; Newman et al., 2014a). Yet to date, little work has examined the role of psychological capital for entrepreneurs (Hmieleski et al., 2015), or its influence in combination with other resources. Integrating human capital and social capital perspectives, this study views psychological capital as a catalyst influencing deployment of entrepreneurs' resources toward venture performance.

This study makes several contributions. First, it brings together the psychological capital and social network literatures with a third domain regarding resource substitution as an entrepreneurial strategy (Clarysse et al., 2011). The results suggest two types of entrepreneur in modern China, the individualistic independent entrepreneur and the interdependent networked entrepreneur. In addition, the study expands the limited work examining main effects of psychological capital on venture performance, especially amid a dearth of research on smallscale entrepreneurship in emerging markets (Bruton et al., 2008, 2017). Finally, the results add useful nuances to the understanding of social capital by demonstrating negative and positive impacts of network ties for entrepreneurs (Gedajlovic et al., 2013; Hoang \& Yi, 2016) in a context where guanxi social ties are very important (Bian, 2017, Lin, 2017). 


\section{THEORY AND HYPOTHESES}

Both general and specific human capital assets such as education, prior employment, and entrepreneurial experience typically have a positive relationship with firm performance (Crook et al., 2011; Marvel et al., 2016), including among entrepreneurial ventures (Unger et al., 2011). Formal schooling enhances the entrepreneur's knowledge base and ability to adapt to new circumstances (Estrin et al., 2016), improves problem-solving ability (Lee \& Tsang, 2001) and raises productivity (Brüderl et al., 1992). Entrepreneurs also benefit from industry employment experience by gaining specific knowledge of products, processes, and markets (Cooper et al., 1994) and strengthening forecasting skills (Cassar, 2014). Previous start-up experience builds tacit knowledge (Dimov, 2010), improving understanding of the entrepreneurial process (Wright et al., 1998). Among small-scale entrepreneurs in China, where recent entrepreneurial traditions are limited (Atherton \& Newman, 2016), human capital derived from education and experience should confer unique advantages. Based on the research, three baseline hypotheses are proposed:

Hla, HIb and HIc: Education level, start-up experience, and industry work experience of entrepreneurs are positively associated with venture growth.

\section{Social Capital and Growth}

Social capital is defined as networks of relationships and the assets located within these networks (Bourdieu, 1986; Coleman, 1988). Entrepreneurs' social ties provide access to strategic resources (Gedajlovic et al., 2013) to enhance competitive advantage and performance (Hernández-Carrión et al., 2017), with networks serving as pathways to specific resources such as business advice, supplies, or socio-emotional support (Bian, 2017; Hoang \& Yi, 2015).

Business advice contacts provide entrepreneurs with guidance on opportunities, suppliers, customers, and personnel (Guo \& Miller, 2010; Ozgen \& Baron, 2007; Fang et al, 2015); such networks facilitate flows of information (Lin 2001) supporting innovation, product launch, and market entry (Hernández-Carrión et al., 2017). Entrepreneurs' network contacts also provide emotional support (Renzulli \& Aldrich, 2005) with social ties acting as confidantes (Jack, 2005) and sources of encouragement (Davidsson \& Honig, 2003), improving venture outcomes (Bosma et al., 2004; Brüderl \& Preisendörfer, 1998). Despite the value of these resources (Batjargal, 2003; Lin, 2001), research tends to examine structural dimensions of networks without differentiating business and emotional resources, yielding inconsistent results (Stam et al., 2014).

Network size, the number of direct links between the main actor and others, quantifies resources that an individual can access (Hoang \& Yi, 2015). A greater number of business advice ties enhances access to broader information on markets, clients, trends, and finance (Cope et al., 2007; Ozgen \& Baron, 2007). In contrast, size is not necessarily a virtue in emotional support networks due to the commitment required. Too many personal contacts distract from profitable activity and generate demands, so that the cost of maintaining a large personal network may outpace benefits, harming performance (Batjargal et al., 2009). Thus, the current study proposes advantages to larger business advice networks and disadvantages to larger emotional networks.

Tie strength, or the relational strength of the direct tie between a main actor and contacts, reflects the level of intimacy in a relationship, based on perceived closeness, duration, and frequency of interaction (Burt, 1992; Granovetter, 1983). High levels of tie strength in emotional support networks yield benefits for entrepreneurs, e.g., as a basis of personal exchange to cope 
with stress (Anderson et al., 2007). Conversely, tie strength beyond a basic threshold is not useful for business advice ties which become too close, requiring maintenance (Bradley et al., 2012) and limiting exposure to new information (Burt, 2004). The dual nature of social capital generates both liabilities and opportunities ( $\mathrm{Li}, 2007)$ as strong ties demand investments that overwhelm benefits received, restricting growth (Kreiser et al., 2013; Sigmund et al., 2015).

In China, social ties are viewed through the lens of guanxi, particularistic ties reflecting levels of trust and obligation (Lin, 2017; Luo et al., 2012; Tsui \& Fahr, 1997). Emotional support networks are likely to emerge from guanxi involving significant personal investment (Bian, 2017; Chen et al., 2013); yet, maintaining a large number of such relationships is unlikely to increase business efficiency (Kim et al., 2013). In contrast, business advice networks often develop among colleagues engaged in instrumental reciprocity (Farh et al., 1998; Luo et al., 2012), where a greater number of ties is useful. The reverse is true for tie strength. When emotional ties are weak, they suggest low-quality guanxi (Chen et al., 2013), obligatory ties that provide little support. Conversely, high tie strength among business networks generates costs such as favors while reducing novel benefits and information (Lin, 2001; Adler \& Kwon, 2002).

\section{H2a: Business advice network size is positively associated with venture growth.}

H2b: Emotional support network size is negatively associated with growth.

H2c: Business advice network tie strength is negatively associated with growth.

H2d: Emotional support network tie strength is positively associated with growth.

\section{Psychological Capital and Growth}

Psychological capital exhibits positive links to individual outcomes and, to some degree, firm outcomes (Avey et al., 2011; Newman et al., 2014a), improving behavior and performance in established firms (Chen \& Lim, 2012; Peterson et al., 2011). To date, a few studies indicate psychological capital's positive effect on growth and well-being among entrepreneurs in the US (Baron et al., 2016; Hmieleski et al., 2015); however, the construct has not been widely studied among entrepreneurs or emerging economies. Psychological capital is relevant to both, as it provides internal resources to deal with the challenges of entrepreneurship (Newman et al., 2014b), especially in difficult environments (Luthans \& Ibrayeva, 2006). It motivates individuals to work harder to overcome obstacles and achieve goals (Avey et al., 2011) through the four subdimensions of self-efficacy, optimism, hope, and resilience.

\section{H3: Psychological capital of entrepreneurs is positively associated with venture growth.}

While research has explored contingencies to the psychological capital-performance link, the construct itself has rarely been employed as a moderator. Yet psychological capital is conceptualized as a motivational resource (Newman et al., 2014a), with potential to amplify positive influences and neutralize negative ones (Abbas, 2013; Baron et al., 2016; Roberts et al., 2011). In the current study, psychological capital is expected to enhance positive effects of human capital. In order for ventures to achieve performance, entrepreneurs must be motivated to deploy resources in pursuit of business goals (Coff \& Kryscynski, 2011; Hmieleski \& Corbett, 
2008). The positive beliefs inherent in psychological capital should motivate individuals to apply knowledge and skills gained through education and experience toward successful outcomes.

H4a, H4b, H4c: The positive effect of education, start-up experience, and industry work experience on venture growth is stronger at higher levels of psychological capital.

While large business advice networks generate positive effects from broad access to information, psychological capital should provide entrepreneurs with the motivation to engage effectively with contacts, extracting resources and putting social capital to use (Newman et al., 2014b). When large emotional networks generate demands, entrepreneurs with psychological capital can set limits on activities that do not generate value, resisting undue obligations. Similarly, psychological capital is expected to buffer the ill effect of claustrophobic business ties as individuals high in psychological capital have the willpower to negotiate demands, extracting useful advice while setting limits on favors expected in return (Abbas et al., 2013; Zou et al., 2016). While strong emotional ties provide support, psychological capital should help channel the benefits of these personal relationships without sacrificing business goals.

H5a and H5d: The positive association between business advice network size and venture growth, and between emotional support network tie strength and venture growth, is stronger at higher levels of psychological capital.

$H 5 b$ and H5c: The negative association between emotional support network size and venture growth, and between business advice network tie strength and venture growth, is weaker at higher levels of psychological capital.

\section{METHODS}

A large financial institution in Zhejiang Province provided access to firms across sectors and allowed separate collection of performance data, while data collection from loan recipients provided a control for financial capital to better test effects of other capitals. A questionnaire was developed in English and translated into Mandarin using back-translation (Brislin, 1993). Faceto-face surveys were conducted with 164 entrepreneurs, a response rate of $54.8 \%$. Within two months, data were validated by re-administering sections of the questionnaire by telephone to a random group of 31 respondents, with an agreement rate of $90 \%$. Multiple imputation (Graham et al., 2003) was used for missing data and hierarchical regression conducted on a pooled dataset (Mishina et al., 2010). Measures included the following:

Revenue Growth. Respondents provided revenue growth as a percentage for the last four years, or since firm founding if under four years; percentages were totaled and divided by years (Arregle et al., 2013). As a check, a firm performance rating was collected from the lender.

Human Capital. Respondents provided their highest level of education (primary, junior high, senior high, junior college, university). Binary dummy variables were created $(0=$ no, 1=yes) for start-up experience and work experience in the same industry (Cassar, 2014).

Social Networks. Using the name generator method, respondents generate names of key contacts who provide specific resources, followed by name interpreters describing the nature of 
the tie (Burt, 2010). In this study, data were collected on two types of 'ego-centric' networks (i.e., direct ties): business advice and emotional support, with the entrepreneur listing surnames of up to five people who provided each resource. Two variables, business advice network size and emotional support network size, were based on the number of contacts named for each resource. Two further variables were calculated from respondents' reports on the closeness of each bond, years known, and communication frequency. Each of the three items was averaged, then standardized and aggregated to generate "business advice network tie strength" and "emotional support network tie strength" for each entrepreneur.

Psychological Capital. The 24-item 'PsyCap' questionnaire (Luthans \& Youssef, 2007) was used, with six questions for each of four sub-dimensions: self-efficacy, optimism, resilience, and hope. Minor adjustments were made to tailor items to entrepreneurs (Luthans et al., 2008b).

Control Variables. These are firm age, firm size, loan size, and respondent age and sex.

To control for common method variance, firm performance data were also collected from the lender; outcomes correlated at .40 to .60. Data were validated by re-interviewing $18 \%$ of respondents, with $90 \%$ agreement on key items. Harman's one-factor test was done, with main variables undergoing exploratory factor analysis. In unrotated principal components analysis, no dominant factor emerged; six factors had eigenvalues $>1$ with the first factor accounting for $13.8 \%$ of variance (Podsakoff et al., 2003). Predictor variables tested negative for curvilinearity, except for emotional network size. From zero, a small number of emotional ties contribute to growth but turn negative as the network grows. For simplicity, the effect is treated as negative.

The psychological capital measure was tested for consistency, with Cronbach's alpha for self-efficacy $\alpha=.78$, hope $\alpha=.71$, resilience $\alpha=.69$, and optimism $\alpha=.70$, and the total for four sub-dimensions on one higher-order factor, $\alpha=.84$. Based on preliminary tests, four items were deleted including reverse-worded questions; similar adaptations to 'PsyCap' have been seen or recommended (Dawkins et al., 2013; Luthans et al., 2008b). A one-factor CFA examined fit of four sub-dimensions on the higher-order construct $(\mathrm{CFI}=1.00, \mathrm{RMSEA}=.001)$ and a four-factor model loading 20 items on four sub-dimensions ( $\mathrm{CFI}=.93$, RMSEA=.086), within acceptable limits. This analysis uses the higher-order psychological capital construct as the stronger model.

The use of multi-year growth data and a time-lagged validation procedure help to control for possible endogeneity. In addition, the findings, in which growth occurs despite lower levels of psychological or social resources, argue against reverse causality.

\section{RESULTS}

The control variables show significant effects on revenue growth for firm age $(\beta=-.09$, $\mathrm{p}<.05)$, firm size $(\beta=.29, \mathrm{p}<.01)$, and loan size $(\beta=-.08, \mathrm{p}<.05)$ and non-significant effects from age and gender (both $\beta=-.01$ ). For human capital, entrepreneur's level of education is positively and significantly linked to growth $(\beta=.27, \mathrm{p}<.01)$, supporting H1a. Start-up experience and industry work experience are not significant, failing to support H1b and H1c. For social capital, business advice network size positively affects growth, supporting $\mathrm{H} 2 \mathrm{a}(\beta=.15, \mathrm{p}<.01)$ while emotional support network size is negatively linked, supporting $\mathrm{H} 2 \mathrm{~b}(\beta=-.08, \mathrm{p}<.05)$. Business network tie strength negatively affects growth, supporting $\mathrm{H} 2 \mathrm{c}(\beta=-.14, \mathrm{p}<.01)$ and emotional network tie strength positively affects growth, supporting $\mathrm{H} 2 \mathrm{~d}(\beta=.13, \mathrm{p}<.01)$. Psychological capital has a significant positive main effect on growth $(\beta=.27, p<.01)$, confirming H3. 
The interaction of psychological capital and education yields a positive result $(\beta=.38$, $\mathrm{p}<.01$ ), confirming H4a. While the interaction of psychological capital and start-up experience is not significant $(\beta=.02 \mathrm{~ns}$ ), failing to support $\mathrm{H} 4 \mathrm{~b}$, the interaction with industry experience turns the non-significant main effect positive $(\beta=.08, \mathrm{p}<.05)$, supporting H4c. Contrary to prediction, a significant negative interaction occurs for psychological capital with business advice network size $(\beta=-.11, p<.01)$ and with psychological capital and business advice network tie strength $(\beta=$ $-.27, \mathrm{p}<.01)$. Thus H5a and H5c are not supported, with significant opposite effects occurring. As expected, the interaction of psychological capital and emotional support network size is positive and significant $(\beta=.13, p<.01)$, supporting H5b. The interaction between psychological capital and emotional support network tie strength is not significant $(\beta=.02 \mathrm{~ns}$ ), failing to support H5d.

\section{DISCUSSION AND CONCLUSION}

As predicted, entrepreneur's education, business advice network size, emotional support network tie strength, and psychological capital have positive effects on growth, while emotional support network size and business advice network tie strength have negative effects. The results reveal positive and negative aspects of different network resources, differentiated by size and strength. This helps explain inconsistent effects of social networks on venture outcomes in previous research, as the debate regarding strong and weak ties does not explicitly examine the resource dimension (Bradley et al., 2012; Davidsson \& Honig 2003). Yet this distinction is important: whether social ties are an advantage or disadvantage depends upon network size and strength for specific resources accessed. Size is an advantage for business advice networks but not for emotional support networks, while the reverse is true for tie strength.

As an amplifier, psychological capital enhances benefits of education, as those high in psychological resources experience synergistic effects on growth. Industry work experience becomes more useful in the presence of high psychological capital, while entrepreneurs low in psychological resources do not benefit. As a buffer, psychological capital reduces 'drag' from large emotional networks, while individuals with fewer psychological resources are not buffered.

Yet psychological capital neither amplifies positive effects of large business networks nor buffers negative effects of close business ties. Rather, entrepreneurs lacking psychological assets benefit from larger and stronger business networks, while those high in psychological capital experience less benefit or even negative impact, suggesting a compensating or substitution effect. For less confident entrepreneurs, more business ties and closer business ties substitute for lack of psychological resources to boost performance. This helps explain why certain network dimensions predict performance only some of the time, contingent on psychological capital.

Resource substitution offers a mechanism to explain how entrepreneurs address scarcity, as firms can succeed if "constraints in some resources are compensated by strengths in other(s)" (Clarysse et al., 2011: 152). For instance, technology, financial capital, and human capital may substitute for each other (Clarysse et al., 2011; Xiao \& Ramsden, 2016). Firms lacking internal resources leverage external ones, reflecting theory that social capital may act as a complement or substitute (Adler \& Kwon, 2002). Resource substitution is especially relevant to small-scale entrepreneurs in emerging economies, where entrepreneurship occurs from necessity as well as opportunity and business is embedded in social relationships. This study adds empirical proof to these concepts, extending the substitutive model to social networks and psychological capital.

\section{REFERENCES AVAILABLE FROM THE AUTHOR}

